\section{Real competence and conformity in a compound stimuli paired-associate learning situation}

ROBERT S. SOBEL, University of Illinois, Urbana, Ill. 61801

Subjects choice of stimulus type in a paired-associates lcarning task was either unanimously opposed by two confederates or was opposed by one and supported by the other. In learning a second list, significantly more $S$ s switched stimulus types in the unanimous opposition condition. The relationship between real competence and conformity did not reach significance, both when competence was divided at the median $S$ and at the extreme quartiles, although all tests were in the predicted direction. By administering response tests at a subsequent session, it was discovered that the private attitudes of Ss corresponded to their public attitudes.

Research has invariably indicated that perceived competence is negatively related to conforming behavior. This relationship has been found for several experimental tasks, including tachistoscopic nonsense-syllable presentation (Samelson, 1957), case history predictions (Hochbaum, 1954), attitude items (DiVesta, 1959), objective stimuli (Rosenberg, 1963), and the autokinetic effect (Kelman, 1950).

In these studies, perceived competence relative to other group members was induced by $\mathrm{E}$ communications; Ss were told that they were either more or less competent than other group members. This type of design introduces a demand characteristic that may affect the experimental outcome. When the $E$ tells a $S$ that he is more able than his associates, the $S$ may interpret this communication to indicate that the $\mathrm{E}$ expects him to be independent. And when the $S$ is told he is less competent, he may interpret the message to indicate that the $\mathrm{E}$ believes he should conform. In addition, the generalizability of these results is weakened because, with the exception of Hollander (1960), only the extremes along the competence continuum have been manipulated.

While previous studies have dealt with perceived relative competence induced through $\mathrm{E}$ communications, the present paper is concerned with the relationship between real competence and conformity in a compound-stimuli paired-associates situation. Using this procedure, competence is a function of the individual's perception of his performance; it is not manipulated by the E. Since Ss have a written record of their accuracy on the paired-associates test trial, their perception of their real competence accurately reflects performance. If we assume that Ss have internal standards of success and failure, it seems reasonable to hypothesize that $\mathrm{Ss}$ who subjectively experience success will be less susceptible to social influence than Ss who experience subjective failure. Thus, direct evidence of relative competence may not be a necessary precondition to conformity differences due to real competence.

In addition, conformity involves more than verbal agreement with the group decision. It is manifested by a change in the S's task-relevant behaviors. In addition to lessening E-induced demand characteristics, this type of paradigm allows an examination of a wide range of competence. Furthermore, the utilization of compound stimuli provides a ready method for differentiating between public conformity and private conformity. Although the significance of such a differentiation has long been recognized, the experimental methods employed have either measured the private response in a postexperimental setting or elicited the public and private responses simultaneously during the experiment. The former method ignores cognitive influences during the postexperimental time interval and the latter ignores the dissonance created by emitting contradictory responses in rapid succession.

The present study creates a situation in which the $S$ can indicate oral agreement with his associates (public conformity) while privately behoving in a fashion that deviates from the preferences of his associates (private nonconformity). This behavior, indicative of the private attitude, may be measured in a postexperimental session with virtually no effect from intervening cognitive influences. Furthermore, the $\mathrm{S}$ has no reason to believe that his associates or the $E$ can detect the fact that he is behaving in a noncompliant fashion.

The aim of the study, then, is to determine the relationship between real competence and the incidence of public and private conformity in a paired-associate learning situation.

\section{SUBJECTS}

Fifty male students enrolled in the introductory psychology class at the
University of Illinois served as experimental Ss.

MATERIALS AND APPARATUS

Two compound-stimuli paired-associates lists were constructed. The stimuli for each item consisted of a color that appeared in the upper left-hand comer of each slide and a three-letter word that appeared in the lower left-hand corner of each slide. Each response was a three-letter word and appeared in the center of the right-hand portion of each slide. Each item was constructed so that associations between each stimulus and the response could be easily formed. For example, the stimuli of one slide included the color "black" and the word "pop," while the response consisted of the word "eye." Note that hoth S.R combinations (black-eye and popeye) arc easy to form and should exhibit high retention percentages.

Also, response test lists were cunsirucled. Each list containcd a randomized order of responses from the original lists.

\section{EXPERIMENT AL GROUP}

Strategy of First Session

The proceduies employed in this sussion were disigned to (1) establish the Ss' preferenci for either words or colors as a stimulus type to be used in learning a paired-associates list, (2) have other group members unanimously oppose the $\mathrm{Ss}^{\prime}$ preference, and (3) provide the $S$ with the opportunity to change his stimulus type preference for a second list (private conformity) and/or his verbal statement of preference (public conformity). If the $\mathrm{S}$ chooses to conform publicly but not privately (i.e., if he continues to use the stimulus type he used on the first list but publicly expresses a change in preference that conforms to the judgment of the other group members), he has no reason to believe that this private nonconformity can be detected either by the $\mathrm{E}$ or the other group members. In the same way, an individual who publicly conforms to group opinion while privately maintaining an unpopular belief has no reason to believe that group members can detect his private nonconformity.

First Session Procedures

Three-person groups, consisting of one $S$ and two paid confederates, were seated in three chairs facing a wall. The confederates took the seats to the right and center, thus forcing the $S$ to take the seat on the left. The group was told that running three $S$ s at the same time was an economically advantageous procedure.

The E explained the compound-stimuli paired-associates learning procedure to be used (RT technique) and told the group that each member was to choose the stimulus type (word or colors) he thought 
would be most easy to associate with the responses. If colors were chosen, the $S$ would associate each stimulus color on the left with the response word on the right, ignoring the stimulus words. If words were chosen, the $S$ was to associate each stimulus word on the left with the response word on the right, ignoring the stimulus colors. Once a stimulus type had been chosen, the $S$ was told he must use it for every item on the list. Viewing time was sufficient only to see one stimulus and its response $(.5 \mathrm{sec})$. Test-trial exposure was even briefer $(.25 \mathrm{sec})$ so that the $S$ could notice only one stimulus.

Having completed the study and test trial series for List 1, the middle confederate quietly asked the $S$ which stimulus type he had used. When he received an answer, the middle confederate mentioned that he used the other stimulus type and proceeded to ask the first confederate which stimulus type he used. The first confederate replied that he also used the other stimulus type.

Following this contrived conversation, the $E$ announed that a second list would be offered. The group was told that in order to raise their motivation to the maximal level for the second, and more important, list, the group of three that had the highest total number of items correct would receive $\$ 5.00$ per man when the experiment was completed. The group members were told that they could use either stimulus type for the second list, but that again they should make their decisions before the first slide was shown. Following the study- and test-trial series for the second list, both confederates announced that they had continued to use the stimulus type they had used on the first list and the $S$ was asked if he had changed his stimulus type preference.

Second Session Procedures

The Ss returned alone the following day and were shown the responses from the list they had previously learned. They were instructed to say aloud the stimuli that went with each response.

The Ss were capable of recalling only the stimuli they had used in the first session. Thus, Ss who conformed publicly, but not privately, would not be able to name the stimuli of the type they claimed publicly to have used. They could recall stimuli only of the type they did actually use. The use of that stimulus type represented their private opinions during the presentation of the second list; cognitive influences between experimental sessions could not affect the measurement of the private response since this response was operationally defined as the stimulus type actually used. Furthermore, since the Ss had no way of knowing that the $E$ had recorded their public responses during the first session, they should not hesitate to do their best on the response test, even if the type of stimulus they recalled differed from the type they told the other group members they had used.

\section{Control Group}

The procedures for the control group were the same as for the experimental group, except that the confederates did not unanimously oppose the S. Rather, one confederate agreed with the $S$ while the other disagreed.

\section{RESULTS}

Stimulus type switching from List 1 to List 2 was significantly greater under the unanimous opposition condition than under the split opinion condition (Fisher's exact test, $\mathrm{p}=.05$ ). This finding defines the conformity effect and was a necessary prerequisite to the other analyses.

An analysis of variance was performed on the experimental and control group response test data. Treatment effects, word-color choice effects, and the Treatment by Word-Color interaction were not significant. Neither the Treatment by Repeated Measure (number of words and colors correct) nor the triple interaction was significant. The Word-Color Choice by Repeated Measure interaction was highly significant $[F(1,46)=512.85, p<.001]$. $T$ his result indicates that the $S$ s overwhelmingly performed better during the response test on the stimulus type they said they had used. An examination of individual performances showed that all 50 Ss performed best during the response test on the stimulus type they said they had used.

Since all Ss who changed stimulus type under unanimous opposition performed better on the stimulus type they said they had used, their conformity must be considered private as well as public. Likewise, those Ss who did not change stimulus type must be considered to have been independent both publicly and privately.

Competence was dichotomized at the median $\mathrm{S}$ with respect to number of correct items on the first list. In addition, the extreme quartiles were determined and tested against switching in a second test. These tests were conducted separately for the experimental and control conditions. None of the exact tests reached significance at the .05 level. However, the results of all four tests were in the predicted direction; that is, the more competent Ss tended to switch stimulus type less often than the less competent Ss, whether they were opposed unanimously or not.

$$
\begin{gathered}
\text { DISCUSSION } \\
\text { Competence and Conformity }
\end{gathered}
$$

The present investigation failed to find a significant relationship between competence on the learning task and stimulus type switching, both when competence was dichotomized at the median and divided at the extreme quartiles. There are several possible explanations for this result. Perhaps competence is weakly related to conformity in small-group interaction situations. The relationship between competence and conformity found by previous investigators might be an artifact of the demand characteristics created by the $E$ when he tells the $S$ that he performed better or worse than other group members. In addition, these studies dealt with experimentally manipulated perception of relative competence, whereas the present investigation dealt with actual competence.

An equally likely explanation is that real competence is only one of many factors entering the conformity equation. Other variables that have been shown to be relevant are the $S$ 's appraisal of the relative competence of other group members, the motivational needs of the $S$ (particularly $n$-achievement and n-affiliation), some salient aspects of personality structure (e.g., ego-strength, authoritarianism. self-esteem, and introversion-extraversion), and the nature of the task (particulary solution ambiguity). The fact that the results were in the predicted direction suggests that competence may interact with situational, motivational, and personality variables in determining conformity behavior. These relationships warrant further investigation.

Private and Public Conformity

That conformity in the present situation was both public and private is consistent with the literature dealing with conformity in ambiguous situations. Sherif (1935) suggested that in the autokinetic situation the Ss who conformed had internalized a standard of judgment or norm presented by the confederate. The Ss who did not conform were thought to have developed their own standard of judgment. Public, but not private, conformity in such a situation would have little functional utility since there was no objectively correct answer.

Similarly, in the present investigation, the Ss had no objective way of knowing whether words or colors could be more easily associated with the response. Those who switched accepted the judgments of the confederates but had no way of knowing either how well the confederates had done or whether or not the new stimulus type would be better than the old Under such conditions, independent Ss should have no fear of ostracism for not 
switching and conformers shouid not husitate to aduit that they did switch.

Studics in which public, but not private. contormity has been found have used either stimuli to which there was an ubjectively correct answer (Asch. 1956) or have employed attitude statements as stimuli (Festinger, 1957). In the tormer case, al! group nembers except a single naive $S$ give an obviously incorrect answer, and in the latter group members express an opinion opposed to that of the naive $S$. Both conditions produce considerable ego-involvement. The conforming individual, when placed in such a situation, may publicly agree with the group decision for fear of ostracism, while privately retaining his initial opinion.

\section{REFERENCES}

ASCH. S. I: Studics of independence and submission to group pressure: 1. A minority of onc against a unanimous majority. Psychological Monograph, 1956. 70, No. 9.
DiVISTA. $\because$. J. Effects of contidence and motivation on susceptibility of informational social influence. Journal of Abnormal \& Social Psychology. 1959,59. 204-209.

FISTINGER, L. A theory of cognitice dissonance. Evanston. I11: Row, Peterson, 1957. HOCHBAUM, G. $M$. The relationship between group members' self-confidence and their reaction to group pressure to conformity. American Social Review. 1954, 19, 678-687.

HOLLANDER, E. P. Competence and conformity in the acceptance of influence. Journal of Abnormal \& Social Psychology, $1960,61,365-369$.

KELMAN, H. C. Effects of success and failure on "suggestibility" in the autokinetic situation. Journal of Abnormal \& Social Psychology, $1950,45,267-285$

ROSENBERG, L. A. Conformity as a function of confidence in partner. Human Relations, 1963 16, 131-139.

SAMELSON, F. Conforming behavior under two conditions of conflict in the cognitive field. Joumal of Abnormal \& Social Psychology, $1957,55,181-187$.

SHERIF, M. A study of some social factors in perception. Archives of Psychology, 1935, 27, No. 187.

\section{Subject-controlled intertrial intervals}

\section{in concept learning ${ }^{1}$}

\author{
HLRBERT WELLS, University of North \\ Carolina, Greensboro, N.C. 27412
}

Ss were allowed to control their own intertrial interval (ITI) in a two-response concept-learning task. The mean ITI was longer following errors than following correct responses and decreased over trials. The results are compatible with measures of response latency on trials following errors and correct responses. but appear to conflict with results obtained when the length of the ITI is made contingent on the correctness of $S$ 's response.

Erickson and his colleagues (Erickson, Zajkowski, \& Ehmann, 1966; Erickson \& Zajkowski, 1967) have shown that in a concept-learning task, response latencies on trials following errors are longer than those following correct responses. These results provide support for hypothesis-testing models of concept learning, which assign an important role to error trials as occasions for processing information and selecting new hypotheses (e.g., Restle, 1962). It is clear, particularly from Levine's work using the blank-trials task (Levine, 1966) that Ss also profit from information conveyed by correct trials. But the selection of a new hypothesis remains an error-related event. Indeed, Levine
(1966) has suggested that Ss are less efficient in extracting information from errors precisely because the inferential process involved is temporally more demanding.

lt is known empirically that a longer intertrial interval (ITI) facilitates concept-learning performance (Bourne \& Bunderson, 1963; Bourne, Guy, Dodd, \& Justesen, 1965). As Bourne (1966, p. 72) has suggested, hypothesis-testing models would therefore predict more efficient performance when errors are followed by a long ITI and correct responses by a short ITI, than when the contingency is reversed. Bourne, Dodd, Guy, \& Justesen (1968) recently tested this prediction and found no difference between the two response-contingent interval conditions.

But suppose that the $S$ himself is allowed to determine the duration of his ITI on each trial in a self-paced procedure. Would he perform in the way that the theoretical rcasoning above suggests is most efficient? The experiments of Erickson et al $(1966,1967)$ suggest that the process of hypothesis selection after an error continues into the next trial when the ITI is held constant. Conversely, if a rather brief, constant time limit is imposed for the response on each trial, would Ss select a longer ITI following errors?

\section{METHOD}

The concepts to be learned had one relevant dimension. There were two levels of stimulus complexity: three irrelevant dimensions (ID) and five ID. Stimuli for the three-ID problems were geometric figures composed of four trinary dimensions: color (red, green, blue); shape (triangle, circle, square); size (small, medium, large); and shading within the figure (dots, stripes, crosshatching). For the five-ID problems, there were two additional trinary dimensions: the orientation of a black bar in the upper left corner of the slide (vertical, horizontal, diagonal) and the number of black dots in the upper right (one, two, three). At each complexity level, two different problems were used: one with size relevant ("large figures are $A$ "), the other with shading relevant ("stripes are A"). Equal numbers of positive (A) and negative (B) stimuli were presented in random order, but with the restriction that no more than three $A$ or B stimuli occur consecutively.

The stimuli were photographed on 35-mm slides and shown on a rear-projection screen through a Carousel projector with external timing controls. A panel in front of the screen contained two response levers, labeled $A$ and $B$, with a red information feedback (IF) light above each lever.

The $S$ was fully instructed concerning the stimuli and the kind of concept to be learned. On each trial, the stimulus was presented and $4 \mathrm{sec}$ later the IF signal was lighted for $1 \mathrm{sec}$. The $S$ was instructed to respond on each trial before the onset of the IF signal or an error would be counted. There was, on the average, fewer than one such error per S. The Ss were nun to a criterion of 16 consecutive correct responses.

The Ss were provided a distinctive button which, when pressed, activated the projector to present the next trial. The elapsed time between the end of the IF signal and the button press was recorded manually from an electric stopclock. Neither the stimulus nor the IF signal was visible during the ITI.

Sixty introductory psychology students at the University of North Carolina-Greensboro served as a course requirement. An equal number of Ss was assigned to each of the four (two complexity levels by two relevant dimensions) problems.

\section{RESULTS AND DISCUSSION}

Each S's precriterion trials were divided into a first and a second half. The mean posterror and postcorrect ITI within each half was computed for each $S$ and then averaged across all Ss. These data are 